La atención a personas en situación de dependencia Care of dependent people

\title{
I. Rández
}

En los últimos años se ha evidenciado la carencia de un marco común que regule la atención a las personas dependientes. Así, desde el Ministerio de Asuntos Sociales, el IMSERSO, las Entidades representativas del sector y las propias Administraciones de las Comunidades Autónomas, se ha visto la necesidad de establecer un marco normativo que establezca y regule el derecho a una atención de calidad de este colectivo. En el año 2005, el Ministerio de Asuntos Sociales, el IMSERSO elaboró el libro blanco de la dependencia que ha servido de base para la elaboración de la tan esperada "Ley de la Promoción de la Autonomía Personal y Atención a Personas en Situación de Dependencia" (LAAD), que fue aprobada por el Gobierno el 14 de diciembre de 2006 con vigencia desde el 1 de enero de 2007 .

Ese mismo año, el Departamento de Bienestar Social del Gobierno de Navarra, elaboró un documento básico para una nueva Ley Foral de Servicios Sociales, que después del proceso participativo al que fue sometido, sirvió para la elaboración del anteproyecto de la citada Ley y, posteriormente, finalizado el nuevo proceso de participación y recogidas las alegaciones, se elaboró el proyecto de Ley Foral de Servicios Sociales que fue aprobado por el Gobierno de Navarra el mismo día que la aprobación de la LAAD, el 14 de diciembre de 2006 (Ley Foral 15/2006, de 14 de diciembre, de Servicios Sociales).

Ambas leyes conceptualmente son iguales en cuanto al reconocimiento del derecho subjetivo de los ciudadanos y la universalidad de acceso a todas las prestaciones establecidas en el catálogo de servicios como mínimas o básicas según el grado y nivel de dependencia en LAAD y a las prestaciones establecidas como garantizadas en la cartera de servicios sociales (Ley Foral); los elementos que configuran el "Sistema de Autonomía y Atención a la Dependencia" y el "Sistema de 
Servicios Sociales" de la Comunidad Foral de Navarra formados por centros y servicios, públicos y privados; la consecución de la igualdad y de la equidad territorial en cuanto a la distribución de servicios, al establecimiento de un catálogo de servicios (LAAD) y de una cartera de Servicios Sociales (Ley Foral); la elaboración de un programa de atención individual; el establecimiento de unos estándares mínimos de calidad para la autorización de funcionamiento y acreditación (LAAD) u homologación (Ley Foral) de servicios. Se establece también una evaluación de la implantación de los servicios y prestaciones de la cartera de servicios sociales o del Sistema de Autonomía y Atención a la Dependencia (SAAD), a fin de establecer las medidas correctoras pertinentes que den respuesta a las necesidades de estas personas.

Sin embargo, la Ley Foral de Servicios Sociales va mucho más allá que la LAAD. La Ley Foral establece el derecho subjetivo no sólo para las personas en situación de dependencia, como hace la LAAD, sino que extiende su acción protectora para toda la población objeto de intervención en el ámbito de los servicios sociales como son: las personas con discapacidad no dependientes, las personas mayores no dependientes, las personas en situación o riesgo de exclusión, la población inmigrante, la infancia, la familia, las personas víctimas de maltrato, las personas en situación de emergencia social y cualquier persona que en algún momento requiera de la intervención de los servicios sociales. Esta Ley implica el desarrollo de los servicios sociales, una adecuación geográfica, económica, demográfica y sociológica de cada área geográfica, adaptando el modelo general de atención de prestaciones y servicios a la singularidad territorial. Esta dotación de una adecuada cobertura de servicios es imprescindible y complementaria a los otros sistemas de protección social, contribuyendo con ello al desarrollo de un modelo de intervención social necesario para conformar una sociedad cohesionada y mejorar la calidad de vida de la ciudadanía, convirtiendo a los Servicios Sociales en el $4^{\circ}$ pilar del Estado de Bienestar.

La Comunidad Foral se ha adelantado a la LAAD en el desarrollo de políticas de protección social a personas en situación de dependencia mediante la puesta en marcha del Programa integral de apoyo a las personas dependientes y a las familias cuidadoras. En enero de 2007 se ha aprobado y puesto en marcha una ayuda económica destinada a personas con gran dependencia o dependencia severa, con dos modalidades para cada grado:

- Ayuda económica vinculada al servicio para la compra de un servicio profesionalizado o para la contratación de personal. 
- Ayuda económica en el entorno familiar; en este caso no se exige ni la compra ni la contratación de un servicio o de una persona. Exige que una persona de dicho entorno se responsabilice del cuidado de la persona dependiente.

El Estado durante este año sólo va a proteger a los grandes dependientes extendiendo la protección a la dependencia severa entre los años 2008-2011, dependiendo de los niveles de la misma.

La LAAD únicamente regula condiciones básicas de la promoción de la autonomía personal y atención a la dependencia, por lo cual el desarrollo de la acción protectora para las personas en situación de dependencia sólo es posible con la participación y colaboración de todas las Administraciones Públicas (General, Autonómica y Local).

Una de las mayores ventajas de la LAAD es la aprobación de un instrumento único a nivel estatal de valoración de la dependencia (I.V.D.), que mediante la aplicación del baremo acredita la condición de dependencia (con el grado y nivel que le corresponda) para todos los ciudadanos del Estado. Serán los servicios sociales de Atención Primaria los que una vez efectuada dicha valoración, y establecido el dictamen de la misma, elaboren el programa individual de atención (PIA) que establecerá los servicios o prestaciones que al ciudadano le corresponden. Este instrumento junto con el baremo deberá ser aprobado por el Consejo Territorial que se constituyó a tal efecto el 22 de enero de 2007, como punto de partida para la puesta en marcha de la Ley y la implantación del SAAD.

En la LAAD hay una priorización de la oferta de servicios profesionales mediante adjudicación directa o mediante la concesión de una prestación económica vinculada al servicio, para que la persona compre un servicio o la prestación económica de asistencia personal. En aquellos casos en que no existe un servicio ni posibilidad de comprarlo se puede conceder la prestación económica para el entorno familiar destinada a cuidadores no profesionales.

Entre los puntos oscuros de la LAAD están: su falta de concreción en aspectos como el establecimiento de criterios de copago por parte de las personas dependientes; la financiación que el Estado repartirá entre las comunidades autónomas; la financiación que tendrán que aportar la comunidades autónomas para la puesta en marcha de Sistema; y la invasión de competencias de las administraciones autonómicas, ya se esta competencia, en materia de asistencia social, está transferida desde la Administración General del Estado.

Para que la LAAD sea una realidad, la Administración General del Estado necesita del compromiso de todas las 
Administraciones Públicas y de los profesionales, cada uno desde el ámbito de sus competencias para diseñar y poner en marcha unas prestaciones y unos servicios públicos y privados que configuren el Sistema de Autonomía y Atención a la Dependencia, que con plenas garantías técnicas y jurídicas, garantice a los ciudadanos la equidad en el acceso y la igualdad de trato en todo el Estado. 